\title{
Effects of Theophylline on Anesthetized Malignant Hyperthermia-Susceptible Pigs
}

\author{
Marko Fiege, Ralf Weisshorn, Kerstin Kolodzie, Frank Wappler, and Mark U. Gerbershagen \\ Department of Anesthesiology, Hospital Itzehoe, Robert-Koch-Straße 2, 25524 Itzehoe, Germany \\ Correspondence should be addressed to Marko Fiege, m.fiege@kh-itzehoe.de \\ Received 12 May 2011; Accepted 23 August 2011 \\ Academic Editor: Lars Larsson \\ Copyright () 2011 Marko Fiege et al. This is an open access article distributed under the Creative Commons Attribution License, \\ which permits unrestricted use, distribution, and reproduction in any medium, provided the original work is properly cited.
}

Background. Theophylline was shown to induce contracture development in porcine malignant hyperthermia (MH) susceptible (MHS) skeletal muscles in vitro. The purpose of the current study was to investigate the in vivo effects of theophylline in MHS and MH normal (MHN) swine. Methods. MH-trigger-free general anesthesia was performed in MHS and MHN swine. Theophylline was administered intravenously in cumulative doses up to $93.5 \mathrm{mg} \cdot \mathrm{kg}^{-1}$. The clinical occurrence of $\mathrm{MH}$ was defined by changes of central-venous $\mathrm{pCO}_{2}$, central-venous $\mathrm{pH}$, and body core temperature. Results. Theophylline induced comparable clinical alterations in the anesthetized MHS and MHN swine, especially in regard to hemodynamic data. No pig developed hypermetabolism and/or MH according to defined criteria. All animals died with tachycardia followed by ventricular fibrillation. Conclusions. The cumulative theophylline doses used in this study were much higher than doses used therapeutically in humans, as demonstrated by measured blood concentrations. Theophylline is thus not a trigger of MH in genetically determined swine.

\section{Introduction}

Malignant hyperthermia $(\mathrm{MH})$ is an autosomally inherited, potentially lethal myopathy with a heterogeneous etiology that is usually triggered by volatile anesthetics and depolarizing muscle relaxants [1]. It is widely accepted that susceptibility to $\mathrm{MH}$ is caused by abnormal $\mathrm{Ca}^{2+}$ metabolism within the skeletal-muscle fiber. The site of the defect in $\mathrm{MH}$ appears to lie in the $\mathrm{Ca}^{2+}$ release mechanism of the sarcoplasmic reticulum (SR) in skeletal muscle, namely, in the complex of the dihydropyridine (DHPR) and ryanodine receptors (RyR).

$\mathrm{Ca}^{2+}$ homeostasis in skeletal muscle is regulated by a variety of intracellular second-messenger systems. Alterations in some second-messenger systems have been found to be associated with $\mathrm{MH}[2,3]$; the cyclic AMP (cAMP) system also seems to be affected in MH. In skeletal-muscle cells from $\mathrm{MH}$-susceptible (MHS) patients and animals, higher cAMP levels were measured compared to normal (MHN) subjects [4-7].

The mode of action of methylxanthines such as caffeine and theophylline is concentration dependent [8]. While they act by adenosine-receptor antagonism at lower concentrations, at higher concentrations they are also unspecific phosphodiesterase (PDE) inhibitors. PDE inhibitors produce a receptor-independent increase in $\mathrm{Ca}^{2+}$ release from the SR via the RyR in cardiac muscle by decreasing the rate of cAMP degradation. This effect could also be demonstrated in skeletal muscle as an increase in isometric contraction after application of PDE inhibitors [9, 10].

Theophylline (1,3-dimethylxanthine) was shown to induce contracture development in porcine skeletal muscle in vitro [11]. Furthermore, clear differences could be demonstrated between MHN and MHS muscle: MHS muscle developed significantly greater contractures compared to MHN specimens after bolus administration of $3 \mathrm{mmol} \cdot \mathrm{L}^{-1}$ or $5 \mathrm{mmol} \cdot \mathrm{L}^{-1}$ theophylline. These results were comparable with in vitro contracture tests (IVCTs) with caffeine and could be explained by the chemical analogies of both substances. In contrast to caffeine, however, theophylline is a widely used pharmaceutical substance. The purpose of the current study was to investigate the in vivo effects of theophylline in MHS and MHN swine. 


\section{Methods}

After approval by the animal research committee of the University Hospital Hamburg-Eppendorf, 6 MHN German Landrace pigs weighing $39-48 \mathrm{~kg}$, aged 3-5 months, and 6 MHS Pietrain pigs weighing $26-33 \mathrm{~kg}$, aged 3-5 months, from a special breeding farm (Research Station Thalhausen, Technical University Munich, Germany) were investigated. Prior to the study, in all animals genomic DNA was isolated from blood preserved in ethylenediaminetetraacetic acid to check for the presence of the Arg615-Cys point mutation on chromosome 6, indicating MH susceptibility [12].

Swine were fasted overnight with free access to water. General anesthesia was induced by administration of ketamine $10 \mathrm{mg} \cdot \mathrm{kg}^{-1}$ intramuscularly (Ketavet, Pharmacia \& Upjohn, Erlangen, Germany). After insertion of a venous cannula into an ear vein, anesthesia was deepened with propofol $10 \mathrm{mg} \cdot \mathrm{kg}^{-1}$ (Diprivan 2\%, Astra-Zeneca, Plankstadt, Germany) and fentanyl $10 \mu \mathrm{g} \cdot \mathrm{kg}^{-1}$ (Fentanyl-Janssen, Janssen-Cilag, Neuss, Germany) intravenously (i.v.). After tracheotomy and intubation, the lungs were mechanically ventilated with an air/oxygen mixture (fraction of inspired oxygen $\left(\mathrm{FiO}_{2}\right)$ 0.4). Anesthesia was maintained with propofol $10 \mathrm{mg} \cdot \mathrm{kg}^{-1} \cdot \mathrm{h}^{-1}$ and fentanyl $50 \mu \mathrm{g} \cdot \mathrm{kg}^{-1} \cdot \mathrm{h}^{-1}$. Neuromuscular blocking drugs were not administered. A multilumen central-venous line was inserted into the right internaljugular vein. One lumen was used for withdrawal of blood samples and measurement of central-venous pressure (CVP), the second for administration of theophylline and fluid infusion $\left(5-10 \mathrm{~mL} \cdot \mathrm{kg}^{-1} \cdot \mathrm{h}^{-1}\right.$ Ringer's solution), and the third for administration of anesthetics. Cannulas were inserted into both femoral arteries: one was used for withdrawal of blood samples, the other for continuous measurement of arterial pressure and body core temperature (PiCCO, Pulsion Medical Systems, Munich, Germany). Normothermia was maintained by forced-air warming, and rectal and intravascular body temperatures were measured continuously.

A blood-gas analyzer (ABL625, Radiometer, Copenhagen, Denmark) was used for monitoring arterial and venous oxygen saturation, oxygen partial pressure $\left(\mathrm{pO}_{2}\right)$, carbon dioxide partial pressure $\left(\mathrm{pCO}_{2}\right), \mathrm{pH}$, and potassium and lactate levels. Mechanical ventilation was adjusted to maintain venous $\mathrm{pCO}_{2}$ at $46 \pm 4 \mathrm{mmHg}$; the body core temperature was adjusted to $37.5 \pm 0.2^{\circ} \mathrm{C}$ before the experiment was started. Once a steady state was achieved for at least 30 minutes, baseline values were recorded for all variables.

Theophylline (Bronchoparat, Klinge Pharma, Munich, Germany) $1.0 \mathrm{mg} \cdot \mathrm{kg}^{-1}$ was administered as an i.v. bolus. Subsequent doses were given every 10 minutes to reach cumulative doses of $3.5,8.5,18.5,33.5,53.5$, and $93.5 \mathrm{mg} \cdot \mathrm{kg}^{-1}$. The clinical occurrence of $\mathrm{MH}$ was defined by the development of two of three conditions: central-venous $\mathrm{pCO}_{2} \geq 75 \mathrm{mmHg}$, central-venous $\mathrm{pH} \leq 7.20$, and an increase of intravascular body core temperature by $\geq 2.0^{\circ} \mathrm{C}$ as measured using the PiCCO system.

During the experiments, hemodynamic variables (heart rate (HR), mean arterial pressure (MAP), CVP, cardiac output), end-tidal $\mathrm{CO}_{2}$ concentration $\left(\right.$ etCO $\left.{ }_{2}\right)$, rectal and intravascular body temperature $\left({ }^{\circ} \mathrm{C}\right)$, blood-gas concentrations $\left(\mathrm{O}_{2}\right.$ saturation $\left.\left(\mathrm{SaO}_{2}\right), \mathrm{pCO}_{2}, \mathrm{pH}\right)$, and lactate levels were measured every 5 minutes. Every 10 minutes, blood samples were taken for gas-chromatographic measurement of theophylline concentrations. After all experiments were completed, the pigs were killed using 10\% magnesium chloride solution i.v.

Statistical evaluation was performed using a computerbased program (StatView 4.57, Abacus Concepts, Berkeley, CA). All data are presented as median and range. Intergroup variations were calculated with the Mann-Whitney test; intragroup differences were calculated with analysis of variance for repeated measures. If appropriate, subsequent comparisons were performed using Scheffe's posthoc method. Results were considered significant if $P$ values were less than 0.05 .

\section{Results}

Theophylline induced comparable clinical alterations in the anesthetized MHS and MHN swine, especially in regard to hemodynamic data. However, significant differences could not be found between MHS and MHN swine. Moreover, no pig developed hypermetabolism and/or $\mathrm{MH}$ according to the defined criteria. Furthermore, clinical signs of muscular alterations, for example, general muscle rigidity, were not observed in any swine. After cumulative administration of $93.5 \mathrm{mg} \cdot \mathrm{kg}^{-1}$, all animals died with tachycardia and hypotension followed by ventricular fibrillation. The main results are summarized in Figure 1.

The $\mathrm{pCO}_{2}$ and venous $\mathrm{pH}$ did not change after administration of theophylline (Figures $1(\mathrm{a})$ and $1(\mathrm{~b})$ ). The baseline body temperatures of the MHS $\left(37.5^{\circ} \mathrm{C}\right.$ (36.6$\left.38.6^{\circ} \mathrm{C}\right)$ ) and $\mathrm{MHN}$ swine $\left(37.4^{\circ} \mathrm{C}\left(35.8-37.8^{\circ} \mathrm{C}\right)\right)$ as well as lactate levels of $1.8 \mathrm{mmol} \cdot \mathrm{L}^{-1}\left(0.4-3.4 \mathrm{mmol} \cdot \mathrm{L}^{-1}\right)$ in MHS and $1.8 \mathrm{mmol} \cdot \mathrm{L}^{-1}\left(0.8-6.5 \mathrm{mmol} \cdot \mathrm{L}^{-1}\right)$ in $\mathrm{MHN}$ animals remained unchanged. The HR of all swine increased at cumulative doses of $93.5 \mathrm{mg} \cdot \mathrm{kg}^{-1}$ theophylline (Figure 1(c)), while the MAP decreased. In MHS swine MAP decreased from $84.5 \mathrm{mmHg}(60-104 \mathrm{mmHg})$ to $65.5 \mathrm{mmHg}(48-$ $67 \mathrm{mmHg}$ ) after administration of $93.5 \mathrm{mg} \cdot \mathrm{kg}^{-1}$ theophylline. In MHN swine the decrease was more marked, from $84 \mathrm{mmHg}(67-98 \mathrm{mmHg})$ to $53.5 \mathrm{mmHg}(50-68 \mathrm{mmHg})$.

There were no differences in blood theophylline concentrations between MHS and MHN swine. A mean blood concentration of $13.9 \mathrm{mg} \cdot \mathrm{mL}^{-1}\left(12.3-16.2 \mathrm{mg} \cdot \mathrm{mL}^{-1}\right)$ theophylline was found after 30 minutes and a cumulative dose of $8.5 \mathrm{mg} \cdot \mathrm{kg}^{-1}$ (Figure 1(d)). These concentrations lie within the therapeutic range for humans $\left(8-20 \mathrm{mg} \cdot \mathrm{kg}^{-1}\right)$. Ten minutes after the last dose $\left(93.5 \mathrm{mg} \cdot \mathrm{kg}^{-1}\right)$ the mean blood concentration was $122.4 \mathrm{mg} \cdot \mathrm{mL}^{-1}\left(99.3-154.4 \mathrm{mg} \cdot \mathrm{mL}^{-1}\right)$.

\section{Discussion}

The cytoplasmic $\mathrm{Ca}^{2+}$ concentration is regulated by a variety of intracellular second-messenger systems. Alterations in second-messenger systems, for example, the serotonin system or inositol polyphosphates, have been found to be associated with MH $[2,3]$. The cAMP system also appears 


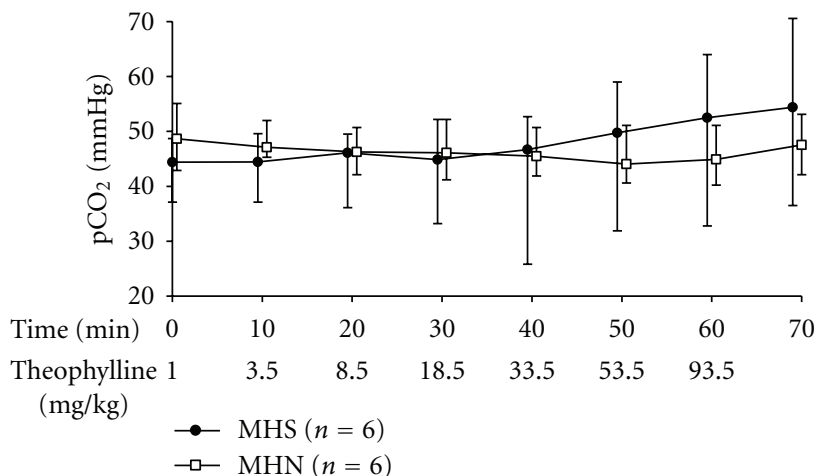

(a)

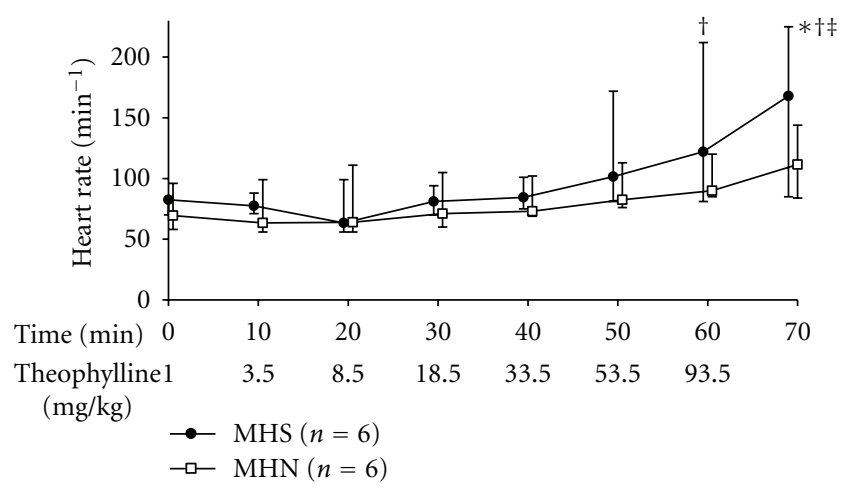

(c)

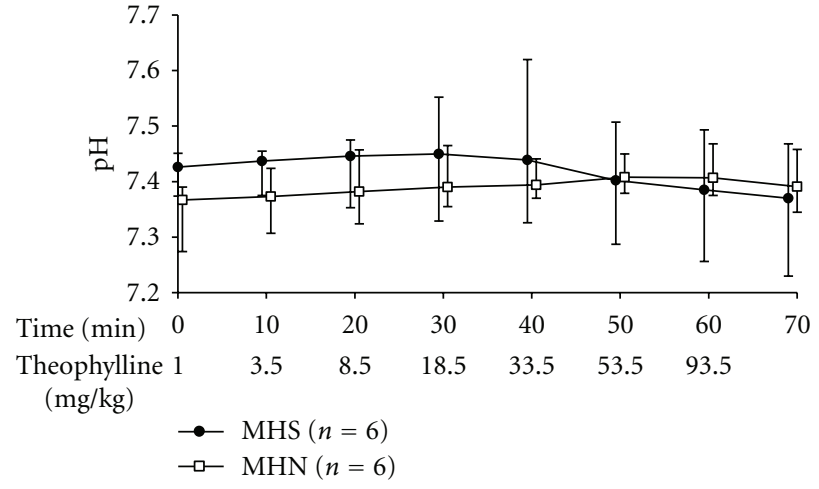

(b)

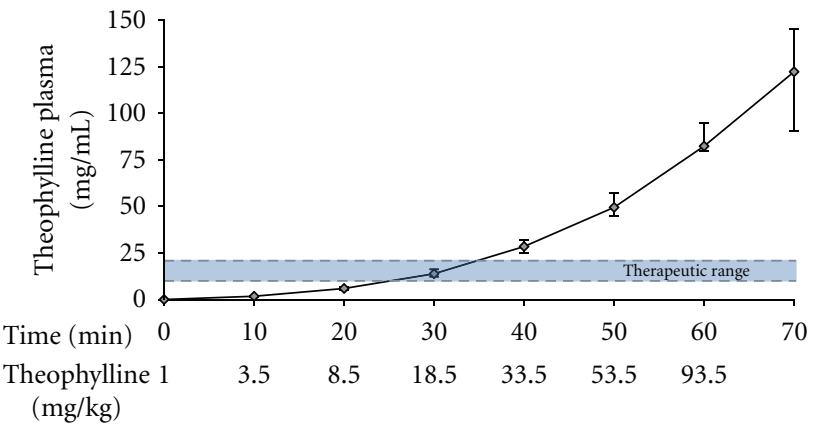

(d)

FIgURE 1: Central-venous $\mathrm{pCO}_{2}$ (a), central-venous $\mathrm{pH}(\mathrm{b})$, heart rate (c), and plasma theophylline concentration (d) following cumulative intravenous administration of theophylline in malignant hyperthermia-susceptible (MHS) and normal (MHN) swine. Shown are median \pm range. ${ }^{*} P<0.05$ MHS versus $\mathrm{MHN} ;{ }^{\dagger} P<0.05$ MHS versus 0 minutes; ${ }^{\ddagger} P<0.05 \mathrm{MHN}$ versus 0 minutes.

to be altered in $\mathrm{MH}$ [4-7]. Higher cytoplasmic cAMP content and adenyl-cyclase activity have been found in MHS compared to MHN patients. Additionally, serum cAMP concentrations during and after physical exercise increased more and for longer time periods in MHS compared to MHN patients [6]. One mode of action of methylxanthines is the unspecific inhibition of PDEs, which leads to enhancement of cytoplasmic cAMP. Furthermore, a MH-specific effect of the methylxanthine caffeine is well known and is used as a gold standard in the IVCTs for the diagnosis of $\mathrm{MH}[10,13]$.

There are several case reports describing patients who developed $\mathrm{MH}$-like symptoms without receiving the classic trigger substances such as succinylcholine or volatile anesthetics [1]. However, MH symptoms are largely unspecific. The clinical presentation of theophylline intoxication can be very similar to $\mathrm{MH}$, for example, with tachycardia, hyperthermia, dehydration, convulsions, and coma as well as skeletal-muscle cramps and rhabdomyolysis. In individual cases, hypermetabolic theophylline overdoses have been treated successfully with dantrolene [14]. Therefore, a possible trigger mechanism of theophylline for $\mathrm{MH}$ was suggested [15].

The MH trigger potential of methylxanthines has been tested in several animal studies. Aminophylline induced $\mathrm{MH}$ like symptoms in anesthetized rabbits, but a genetic basis of MH susceptibility in these animals was not examined in this study [16]. In MHS swine, i.v. and oral administration of caffeine potentiated the development of $\mathrm{MH}$ crises induced by halothane and succinylcholine [17]. It was therefore suggested that caffeine may reduce the threshold of $\mathrm{MH}$ trigger agents. Furthermore, the detection of specific in vitro effects of theophylline in porcine skeletal-muscle preparations supported the hypothesis of an $\mathrm{MH}$ trigger potential for methylxanthines [11].

In this study, theophylline was not a trigger of $\mathrm{MH}$ in susceptible swine. No significant differences between MHS and MHN swine or symptoms of hypermetabolism could be found during cumulative administration of theophylline. The therapeutic blood level of theophylline in humans is estimated at between 8.0 and $20.0 \mathrm{mg} \cdot \mathrm{mL}^{-1}$. After cumulative administration of $93.5 \mathrm{mg}$ theophylline, the swine in our study died in hemodynamic decompensation. The mean blood level measured at this time was $122.4 \mathrm{mg} \cdot \mathrm{mL}^{-1}(99.3-$ $\left.154.4 \mathrm{mg} \cdot \mathrm{mL}^{-1}\right)$ or $0.68 \mathrm{mmol} \cdot \mathrm{L}^{-1}\left(0.55-0.86 \mathrm{mmol} \cdot \mathrm{L}^{-1}\right)$ theophylline. A direct comparison between in vivo blood concentrations and concentrations in IVCTs is impossible. However, in vitro contracture development in isolated porcine MHS muscle specimens started at concentrations of $3.0 \mathrm{mmol} \cdot \mathrm{L}^{-1}$ theophylline. Therefore, it could be speculated that the in vivo theophylline concentrations in this study 
were high enough to kill the animals, but too low to trigger $\mathrm{MH}$.

Theophylline induces a sympathoadrenergic response comparable with a strong stress reaction. Stress is a wellknown trigger of $\mathrm{MH}$ in swine, whereas the role of stress in human $\mathrm{MH}$ is still unclear $[9,18]$. Considering the results of this study, theophylline might be a cofactor in the induction of $\mathrm{MH}$ in humans, but does not appear to be a primary trigger of $\mathrm{MH}$.

\section{References}

[1] F. Wappler, "Anesthesia for patients with a history of malignant hyperthermia," Current Opinion in Anaesthesiology, vol. 23, no. 3, pp. 417-422, 2010.

[2] J. Scholz, U. Troll, J. Schulte Am Esch et al., "Inositol-1,4,5trisphosphate and malignant hyperthermia," The Lancet, vol. 337 , no. 8753 , article 1361, 1991.

[3] F. Wappler, M. Fiege, and J. Schulte am Esch, "Pathophysiological role of the serotonin system in malignant hyperthermia," British Journal of Anaesthesia, vol. 87, no. 5, pp. 794-798, 2001.

[4] J. H. Willner, C. C. Cerri, and D. S. Wood, "High skeletal muscle adenylate cyclase in malignant hyperthermia," The Journal of Clinical Investigation, vol. 68, no. 5, pp. 1119-1124, 1981.

[5] F. R. Ellis, P. J. Halsall, P. Allam, and E. Hay, "A biochemical abnormality found in muscle from unstressed malignanthyperpyrexia-susceptible humans," Biochemical Society Transactions, vol. 12, no. 3, pp. 357-358, 1984.

[6] A. Stanec and G. Stefano, "Cyclic AMP in normal and malignant hyperpyrexia susceptible individuals following exercise," British Journal of Anaesthesia, vol. 56, no. 11, pp. 1243-1246, 1984.

[7] J. Scholz, M. Steinfath, N. Roewer et al., "Biochemical changes in malignant hyperthermia susceptible swine cyclic AMP, inositol phosphates, $\alpha 1, \beta 1$ - and $\beta 2$-adrenoceptors in skeletal and cardiac muscle," Acta Anaesthesiologica Scandinavica, vol. 37, no. 6, pp. 575-583, 1993.

[8] H. Scholz, "Inhibition of phosphodiesterases," Zeitschrift fur Kardiologie, vol. 83, no. 2, pp. 1-5, 1994.

[9] J. Sawynok and T. L. Yaksh, "Caffeine as an analgesic adjuvant: a review of pharmacology and mechanisms of action," Pharmacological Reviews, vol. 45, no. 1, pp. 43-85, 1993.

[10] H. Ørding, V. Brancadoro, S. Cozzolino et al., "In vitro contracture test for diagnosis of malignant hyperthermia following the protocol of the European $\mathrm{MH}$ group: results of testing patients surviving fulminant $\mathrm{MH}$ and unrelated lowrisk subjects," Acta Anaesthesiologica Scandinavica, vol. 41, no. 8, pp. 955-966, 1997.

[11] M. U. Gerbershagen, M. Fiege, R. Weißhorn, K. Kolodzie, and F. Wappler, "Theophylline induces contractures in porcine skeletal muscle preparations with the disposition to malignant hyperthermia," Anasthesiologie Intensivmedizin Notfallmedizin Schmerztherapie, vol. 39, no. 3, pp. 147-152, 2004.

[12] J. Fujii, K. Otsu, F. Zorzato et al., "Identification of a mutation in porcine ryanodine receptor associated with malignant hyperthermia," Science, vol. 253, no. 5018, pp. 448-451, 1991.

[13] M. G. Larach, J. R. Landis, J. S. Bunn, and M. Diaz, "Prediction of malignant hyperthermia susceptibility in low-risk subjects: an epidemiologic investigation of caffeine halothane contracture responses," Anesthesiology, vol. 76, no. 1, pp. 16-27, 1992.
[14] M. J. A. Parr and S. M. Willatts, "Fatal theophylline poisoning with rhabdomyolysis. A potential role for dantrolene treatment," Anaesthesia, vol. 46, no. 7, pp. 557-559, 1991.

[15] E. H. Flewellen and T. E. Nelson, "Is theophylline, aminophylline, or caffeine (methylxanthines) contraindicated in malignant hyperthermia susceptible patients?" Anesthesia and Analgesia, vol. 62, no. 1, pp. 115-118, 1983.

[16] G. S. LeFever and H. Rosenberg, "Aminophylline, halothane, and malignant hyperpyrexia in the rabbit," Fed Proc, vol. 39, article 295, 1980.

[17] J. W. Chapin, G. L. Chang, and D. W. Wingard, "Coffee (caffeine) and porcine malignant hyperthermia," Anesthesiology, vol. 55, no. 3, article A292, 1981.

[18] R. Grinberg, G. Edelist, and A. Gordon, "Postoperative malignant hyperthermia episodes in patients who received 'safe' anaesthetics," Canadian Anaesthetists Society Journal, vol. 30, no. 3, pp. 273-276, 1983. 

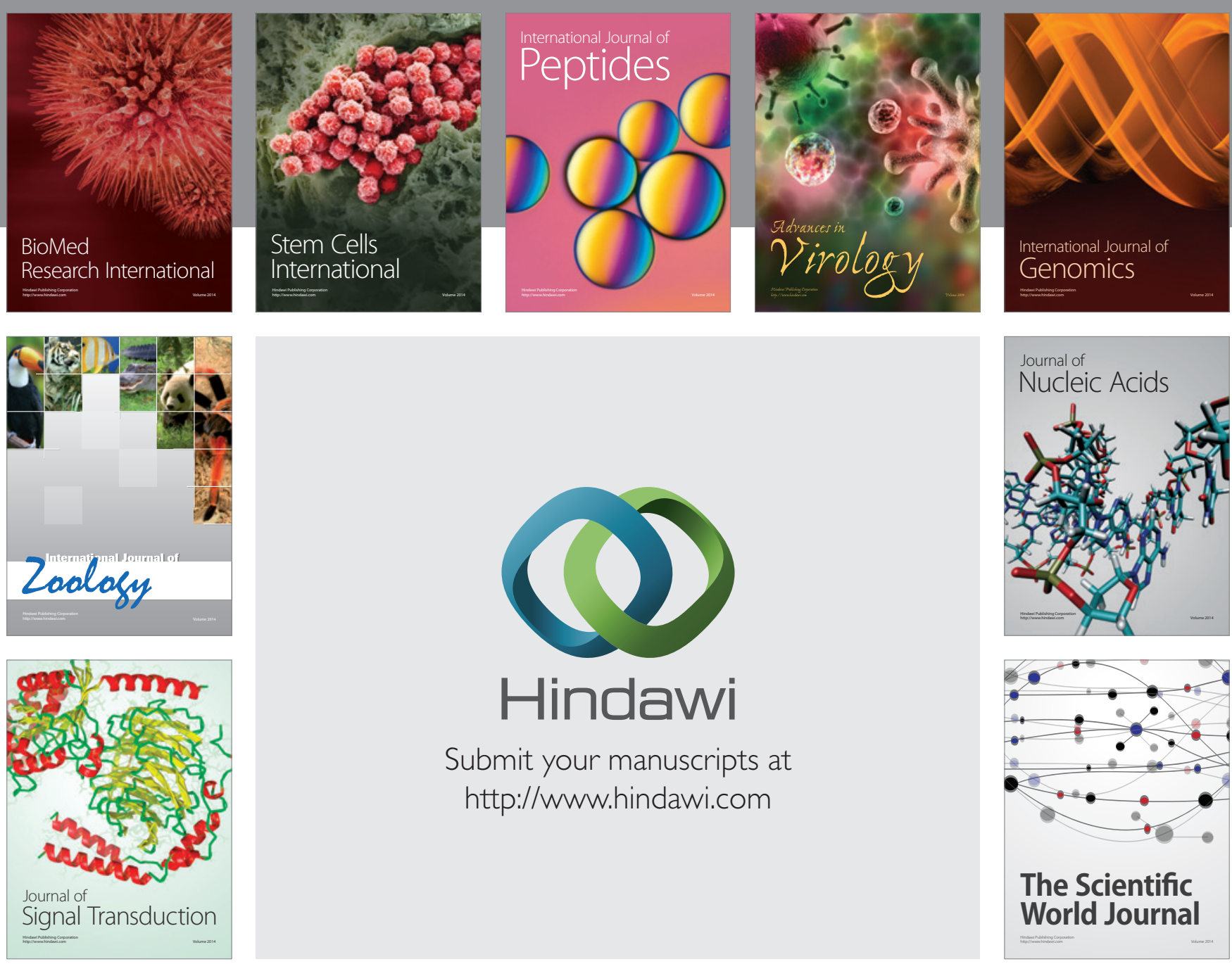

Submit your manuscripts at

http://www.hindawi.com
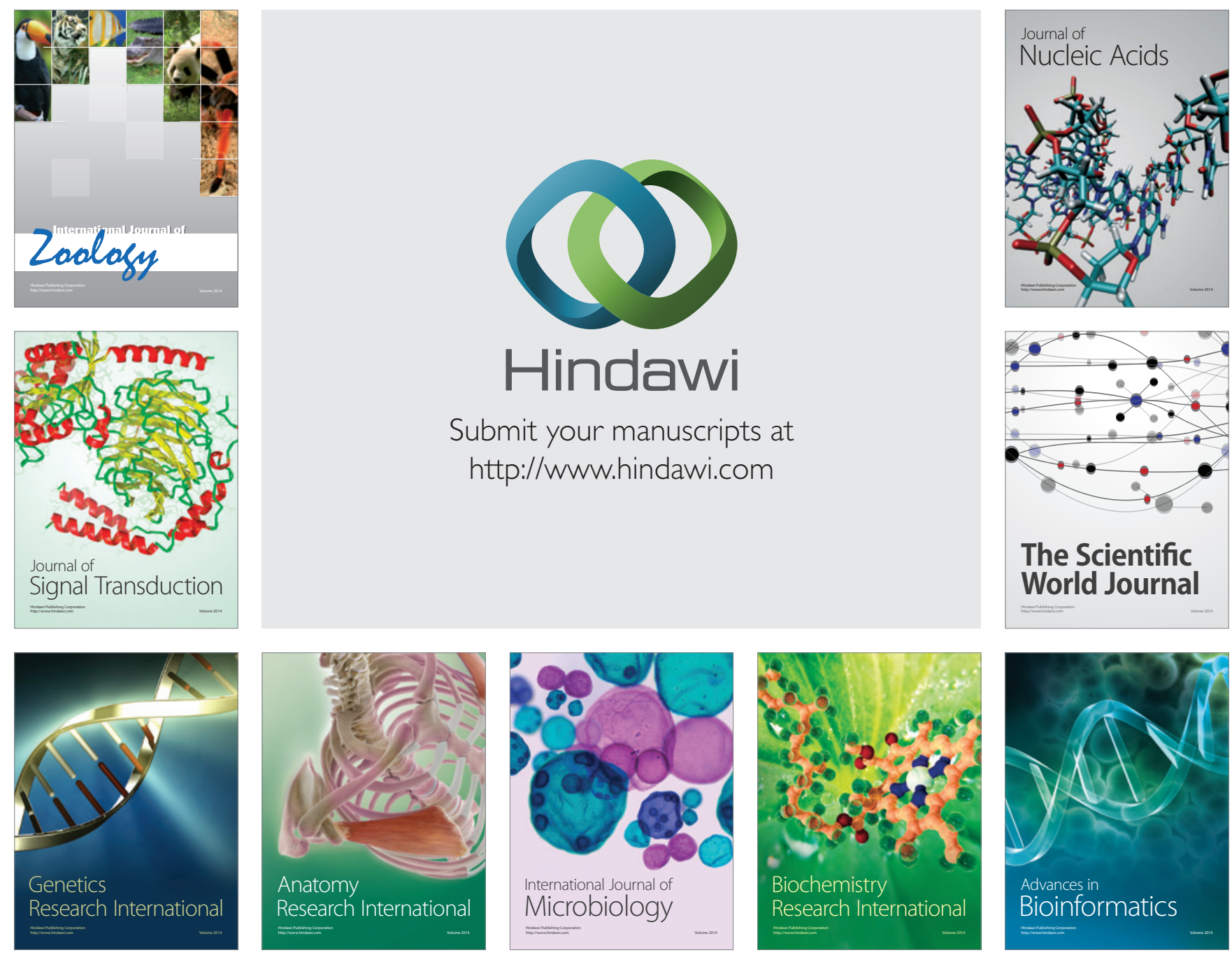

The Scientific World Journal
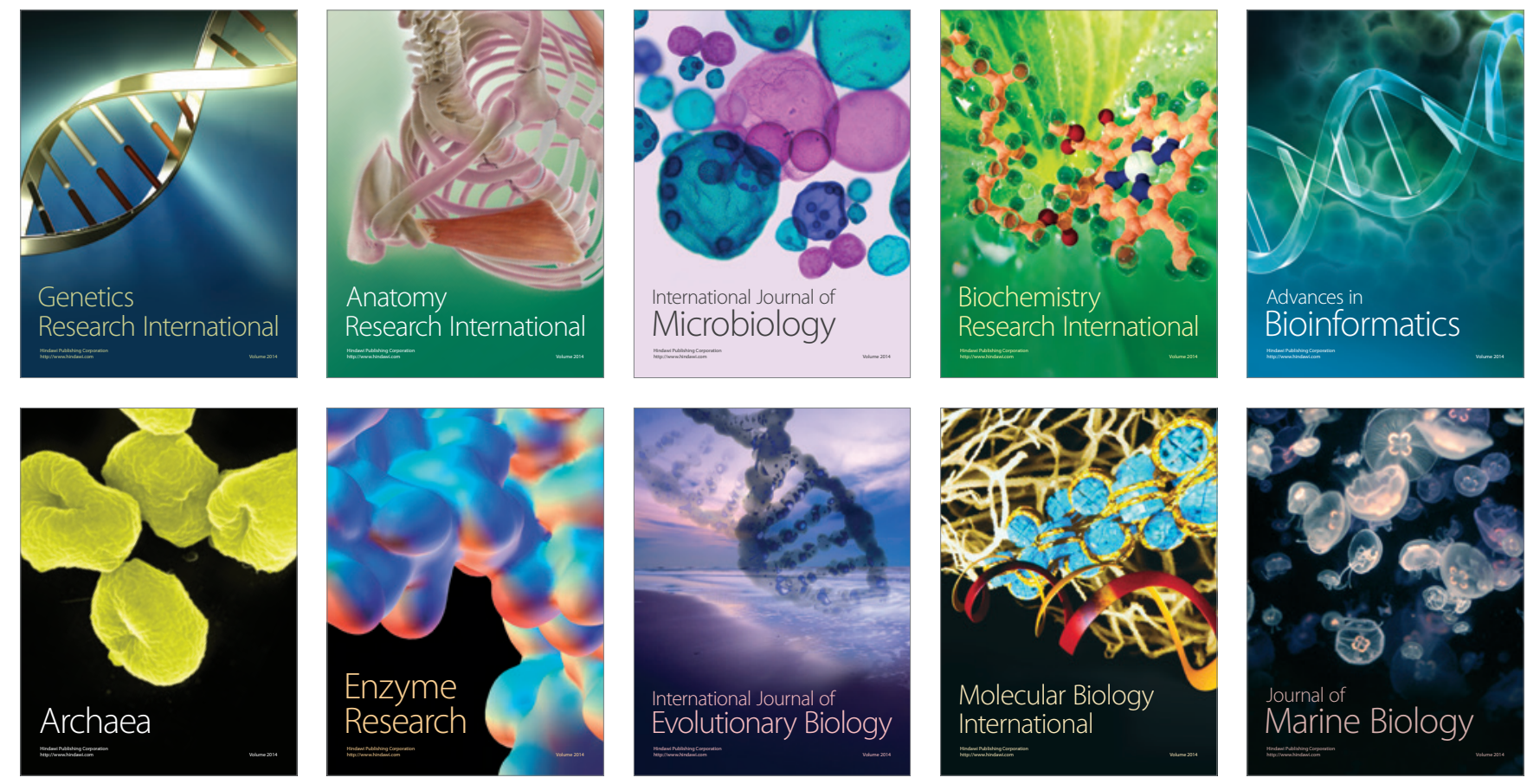